\title{
BMJ Open Relationship of anthropometric measurements to thyroid nodules in a Chinese population
}

Weimin $\mathrm{Xu},{ }^{1}$ Zexin Chen, ${ }^{2} \mathrm{Na} \mathrm{Li},{ }^{3}$ Hui Liu, ${ }^{2}$ Liangliang Huo, ${ }^{1}$ Yangmei Huang, ${ }^{1}$ Xingyi Jin, ${ }^{1}$ Jin Deng, ${ }^{1}$ Sujuan Zhu, ${ }^{1}$ Shanchun Zhang, ${ }^{2}$ Yunxian $\mathrm{Yu}^{2}$

To cite: Xu W, Chen Z, Li N, et al. Relationship of anthropometric measurements to thyroid nodules in a Chinese population. BMJ Open 2015;5:e008452. doi:10.1136/bmjopen-2015008452

- Prepublication history and additional material is available. To view please visit the journal (http://dx.doi.org/ 10.1136/bmjopen-2015008452).

WX and ZC contributed equally.

Received 17 April 2015 Revised 17 September 2015 Accepted 22 October 2015

\section{CrossMark}

For numbered affiliations see end of article.

Correspondence to

Dr Yunxian Yu;

yunxianyu@zju.edu.cn

\section{ABSTRACT}

Objective: Previous studies have found that overweight and obesity are related to numerous diseases, including thyroid cancer and thyroid volume. This study evaluates the relationship between body size and the presence of thyroid nodules in a Chinese population.

Methods: A total of 6793 adults and 2410 children who underwent thyroid ultrasonography were recruited in this cross-sectional study in Hangzhou, Zhejiang Province, China, from March to October, 2010. Sociodemographic characteristics and potential risk factors of thyroid nodules were collected by questionnaire. Height and weight were measured using standard protocols. Associations of height, weight, body mass index (BMI) and body surface area (BSA) with the presence of thyroid nodules were evaluated using multiple logistic regression models.

Results: After adjustment for potential risk factors, an increased risk of thyroid nodule incidence was associated with height (OR 1.15, 95\% Cl 1.02 to 1.30), weight (OR $1.40,95 \% \mathrm{Cl} 1.24$ to 1.58 ), BMI (OR 1.26, 95\% Cl 1.11 to 1.42 ) and BSA (OR 1.43, $95 \% \mathrm{Cl} 1.27$ to 1.62 ) in all adults, but most obviously in women. In children, similar associations were observed between risk of thyroid nodule incidence and weight, BMI and BSA, but not height. BSA was the measurement most significantly associated with thyroid nodules in both adults and children.

Conclusions: This study identified that the presence of thyroid nodules was positively associated with weight, height, BMI and BSA in both women and girls. It suggests that tall, obese individuals have increased susceptibility to thyroid nodules.

Trial registration number: NCT01838629.

\section{INTRODUCTION}

Most thyroid nodules are benign, ${ }^{1}$ but 5-6.5\% are malignant (carcinomas, cancer (CA)). ${ }^{2}$ Because thyroid function is linked to development and growth, height and weight are seen as possible indicators of thyroid nodule risk. Overweight and obesity are major risk factors for a number of chronic

\section{Strengths and limitations of this study}

- Subjects included adults and children.

- Large sample size.

- Weight and standing height were measured using a standardised protocol by a trained examiner rather than being self-reported.

- The main results are presented after adjustment for many potential confounders, including cigarette smoking and alcohol drinking, two important factors that influence overweight.

- The number and size of thyroid nodules were not recorded, and the thyroid nodules were not classified.

diseases, including diabetes, cardiovascular diseases and cancer. They are the fifth leading risk for global deaths. In addition, 7$41 \%$ of certain cancer burdens are attributable to overweight and obesity. ${ }^{3}$ Data from epidemiological studies demonstrate a direct correlation between body mass index (BMI) and the risk of medical complications and mortality rate. ${ }^{5}$ The prevalence of overweight and obesity has been increasing in most economically developed countries for several decades, and there is evidence that it is also increasing in economically developing countries. $^{6} 7$ The prevalence of obesity has recently been increasing dramatically in China as a developing country. A national survey indicates that the prevalence of overweight and obesity, respectively, are $24.1 \%$ and $2.8 \%$ in men and $26.1 \%$ and $5.0 \%$ in women. ${ }^{8}$ Meanwhile, previous studies have reported functional and morphological alterations in the thyroid gland in relation to obesity. ${ }^{9-13}$ As thyroid hormones increase the basal metabolic rate, low thyroid function, even within the clinically normal range, could decrease metabolic speed and lead to obesity. $^{13}{ }^{14}$ In addition, Bastemir et $a l^{12}$ found that serum levels of thyroid-stimulating hormone correlate positively with the degree of obesity and some of its metabolic 
consequences in overweight people with normal thyroid function. Furthermore, Guth et $a l^{15}$ reported that BMI correlated positively with thyroid size. Although the vast majority of nodules are benign, risk factors for thyroid nodules in the euthyroid population have not yet been fully elucidated. A previous study on a Chinese population indicated that overweight (OR 1.199, 95\% CI 1.078 to 1.333 ) might be a risk factor for thyroid nodules after adjustment for age and gender. ${ }^{16}$ Similarly, Guth et al ${ }^{15}$ observed that mean thyroid size correlated strongly with body weight. However, Kim et $a l^{17}$ reported that Korean patients with thyroid nodules were shorter and lighter and had a smaller body surface area (BSA) than those without thyroid nodules. In women in particular, being shorter and overweight were identified as independent risk factors for the presence of thyroid nodules.

Therefore, the association of anthropometric measurements with thyroid nodules is still unclear. Furthermore, previous studies have rarely focused on the relationship of anthropometric measurements with thyroid nodules in Chinese. The aim of our study was to examine the relationship of anthropometric measurements with thyroid nodules in a large sample of a Chinese population.

\section{MATERIALS AND METHODS \\ Population features}

From March to October 2010, this large cross-sectional study was conducted in Hangzhou city, which is one of the largest commercial cities in eastern China. Details of the population have been previously reported. ${ }^{18}$

\section{Subjects and study design}

All participants were recruited on the basis of the following strategies. There are eight districts and five counties in greater Hangzhou. First, three sub-districts or towns were selected randomly from each district or county (except Binjiang district), so 36 sub-districts or towns were selected from greater Hangzhou. Then, one community or village was randomly selected from each sub-district or town. Next, 100 households from each community or village were randomly selected. Finally, we selected 3600 households for interview. The family members of the household were chosen based on the following criteria: (1) age at least 6 years; (2) living for more than 5 years at the present residence. Exclusion criteria were: (1) coronary angiography or endoscopic retrograde cholangiopancreatography in the past 6 months; (2) taking amiodarone; (3) abnormal kidney function or serious illness.

The eligible family members of the selected households were assembled at the village or community administration centre. The researchers introduced the study protocol and obtained written informed consent from each. Meanwhile, interviews were scheduled with the participants. The study protocol was approved by the institutional review board of Hangzhou Center of
Disease Control and Prevention. This survey was carried out by well-trained personnel (including community clinic physicians, nurses, public health doctors).

\section{Collection of epidemiological data}

The participants were interviewed using a structured questionnaire, which covered demographic characteristics and health status, including sex, age, nationality, physical activity, lifestyle, dietary habits, and personal or family history of thyroid disease (including time of diagnosis).

\section{Collection of data on anthropometric measurements and thyroid nodules}

Height and weight were measured using standard protocols, without shoes or outerwear. Height was measured to the nearest $0.1 \mathrm{~cm}$ on a portable stadiometer with a GMCS-I-type tripod. Weight was measured to the nearest $0.1 \mathrm{~kg}$ with the subjects standing motionless on a scale with a balance-beam scale (RGT-140 weighing apparatus; Wuxi). An ultrasound examination of the thyroid was performed to detect thyroid nodules with a Sonoline Versa Pro (Siemens, Munich, Germany) with a $7.5 \mathrm{MHz}$, $70 \mathrm{~mm}$ linear transducer (effective length, $62 \mathrm{~mm}$ ). A thyroid nodule was defined as a discrete lesion that was distinct from the surrounding thyroid parenchyma and which had a solid portion regardless of having a cystic portion.

\section{Body mass index}

The BMI is defined as the weight in kilograms divided by the square of the height in metres. Although the BMI calculation does not take into account factors such as frame size and body tissue composition, BMI categories are generally used to estimate adiposity and assess how much an individual's body weight departs from what is normal or desirable for a person of that height. According to the criteria recommended by the Working Group on Obesity in China, ${ }^{19}$ the classification of BMI for adults was as follows: $\mathrm{BMI}<24$, low (normal and underweight); $24 \leq \mathrm{BMI}$, high (overweight and obese). For children, the reference BMI was calculated using the reference height and weight of each age group. ${ }^{20}$

\section{Body surface area}

BSA is a commonly used index in clinical practice to correct for patient size differences in various physiological measurements and in calculating drug dosage. BSA is a more accurate measure of obesity, including central obesity, as it is a measurement of area and is able to account for the difference between muscle and fat better than BMI secondary to muscle versus fat. ${ }^{21}$ Previous studies have observed an association between BSA and thyroid volume and nodules. ${ }^{17}{ }^{22}$ Various formulas have been proposed for estimating BSA from a patient's weight and height, which may result in slightly different values. ${ }^{23-26}$ The most commonly used formula in day-to-day clinical practice is the Mosteller formula: 
BSA $\left(\mathrm{m}^{2}\right)=($ square root of product of weight $(\mathrm{kg}) \times$ height $(\mathrm{cm})) / 60 .{ }^{25}$ This formula is simplified from one produced by Gehan and George, ${ }^{23}$ and has become a common standard because it is easy to memorise and its use requires only a handheld calculator. So the Mosteller formula was used in our study to calculate BSA.

\section{Definition of variables}

For adults, height, weight, BMI and BSA were dichotomised into a high group and a low group. The detailed criteria of each group are shown in online supplementary table S1. For classification of height and weight for adults, we used The Survey Report on National Physical Fitness of Chinese, 2005. In children, the high group included subjects with height or weight equal to or greater than the reference standard for each age group (1 year a group) for the two genders. BMI was classified according to the reference calculated using the reference height and weight of each age group (1 year a group) for the two genders. ${ }^{20}$ BSA was classified according to the average value for each gender.

\section{Statistical analysis}

Comparison of height, weight and age between patients with and without thyroid nodules was conducted by $\mathrm{t}$ test. Comparisons between groups were made using the $\chi^{2}$ test for qualitative data, including gender, education, marriage, place of residence, cigarette smoking, alcohol drinking, salt appetite, milk consumption, diet patterns and types of salt. Listwise deletion was used to address the missing data in the model.

The adjusted associations of height, weight, BMI and BSA with thyroid nodules were estimated using a logistic regression model stratified by gender. The variables showing a significant difference between the group with and without thyroid nodules were taken as covariates in logistic regression models: age, BMI, educational level, marital status, place of residence, cigarette smoking, alcohol drinking, diet flavour, types of salt, dietary patterns, milk consumption. For adults, age was classified into five classes: $18-29,30-39,40-49,50-59$, $\geq 60$. For children, age was classified into four classes: $6-8,9-11$, 12-14, 15-17. To account for the correlation of members in the same household, we calculated robust estimates of variances with a generalised estimating equation using the SAS procedure GENMOD. All analyses were performed with SAS V.9.0. A value of $p<0.05$ was considered significant.

\section{RESULTS}

\section{Baseline characteristics of study population}

A total of 12438 individuals were recruited, but 3235 were excluded from analysis because of the absence of anthropometric measurements. Final analyses included 9203 subjects (6793 adults and 2410 children). The average age of the adults was 47.93 years; $62.96 \%$ were female, and $4.39 \%, 66.13 \%, 26.34 \%$ and $3.14 \%$ were underweight, normal, overweight and obese, respectively. The sociodemographic characteristics of adult patients with and without thyroid nodules are shown in table 1. Of the 6793 adults, $2228(32.80 \%)$ had thyroid nodules; $71.01 \%$ were women. Subjects with thyroid nodules were older, shorter and more likely to be female $(p<0.001)$. Moreover, the distributions of education, marital status, place of residence, smoking, drinking, salt appetite, milk consumption and diet patterns showed significant differences between the two groups (table 1).

The sociodemographic characteristics of the paediatric patients with and without thyroid nodules are shown in table 2. Subjects with thyroid nodules were older and more likely to be female $(p<0.05)$. The distributions of place of residence, salt appetite and types of salt showed significant differences between the two groups (table 2). Among the children, $47.55 \%$ were under the reference BMI and $52.45 \%$ were over the reference BMI. In total, $257(10.66 \%)$ children had thyroid nodules; more than half $(57.98 \%)$ were girls (table 2$)$.

Relationship between anthropometric measurements and thyroid nodules in adults

Relationships between anthropometric measurements (height, weight, BMI, BSA) and thyroid nodules were estimated by gender (table 3). According to the pooled results, height (OR 1.15, 95\% CI 1.02 to 1.30), weight (OR $1.40,95 \%$ CI 1.24 to 1.58 ), BMI (OR $1.26,95 \%$ CI 1.11 to 1.42 ) and BSA (OR $1.43,95 \%$ CI 1.27 to 1.62 ) were significantly associated with an increased risk of thyroid nodules. Similar trends were observed in the separate female and male groups, but no significant association was seen in men. The associations with tertiles of exposure (height, weight, BMI, BSA) were very similar to previous findings when subjects diagnosed with thyroid diseases were excluded (see online supplementary table S2).

\section{Relationship between anthropometric measurements and thyroid nodules in children}

Relationships between anthropometric measurements and thyroid nodules were also determined in children (table 4). According to the pooled results, weight (OR $1.37,95 \%$ CI 1.03 to 1.81 ), BMI (OR $1.38,95 \%$ CI 1.04 to 1.83 ) and BSA (OR 2.97, 95\% CI 1.85 to 4.77 ) were significantly associated with thyroid nodules. The significant association of BSA with thyroid nodules was observed in both boys (OR 2.57, 95\% CI 1.25 to 5.28) and girls (OR 3.36, 95\% CI 1.82 to 6.20); BMI and weight were also positively related to thyroid nodules in both genders, but a significant association of BMI was observed in boys and a significant association of weight was observed in girls. No significant association was observed between height and thyroid nodules. 
Table 1 Distributions of sociodemographic characteristics among adult patients with and without thyroid nodules

\begin{tabular}{|c|c|c|c|}
\hline Variable & $\begin{array}{l}\text { Nodules } \\
(n=2228)\end{array}$ & $\begin{array}{l}\text { No nodules } \\
(n=4565)\end{array}$ & p Value \\
\hline Age, years & $53.49 \pm 13.80$ & $44.93 \pm 13.72$ & $<0.001$ \\
\hline Height, cm & $160.72 \pm 7.25$ & $162.24 \pm 7.54$ & $<0.001$ \\
\hline Weight, kg & $59.30 \pm 8.12$ & $59.10 \pm 8.33$ & 0.177 \\
\hline BMI, $\mathrm{kg} / \mathrm{m}^{2}$ & $23.07 \pm 2.69$ & $22.52 \pm 2.65$ & $<0.001$ \\
\hline \multicolumn{4}{|l|}{ Gender } \\
\hline Male & $646(28.99)$ & $1870(40.96)$ & \multirow[t]{2}{*}{$<0.001$} \\
\hline Female & $1582(71.01)$ & 2695 (59.04) & \\
\hline \multicolumn{4}{|l|}{ Education* } \\
\hline Primary school & $922(42.10)$ & $1317(29.15)$ & \multirow[t]{4}{*}{$<0.001$} \\
\hline Junior high school & 647 (29.54) & $1440(31.87))$ & \\
\hline Senior high school & $470(21.46)$ & $1283(28.40)$ & \\
\hline Junior college and above & $151(6.89)$ & $478(10.58)$ & \\
\hline \multicolumn{4}{|l|}{ Marriage } \\
\hline Single & $78(3.51)$ & $378(8.29)$ & \multirow[t]{5}{*}{$<0.001$} \\
\hline Married & $1980(88.98)$ & 3981 (87.30) & \\
\hline Divorce & $22(0.99)$ & $47(1.03)$ & \\
\hline Widowed & $139(6.25)$ & $140(3.07)$ & \\
\hline Other & $6(0.27)$ & $14(0.31)$ & \\
\hline \multicolumn{4}{|l|}{ Residence location } \\
\hline Urban area & $1214(54.49)$ & $2125(46.55)$ & \multirow[t]{2}{*}{$<0.001$} \\
\hline Rural area & 1014 (45.52) & $2440(53.45)$ & \\
\hline \multicolumn{4}{|l|}{ Cigarette smoking } \\
\hline Never & 1825 (82.65) & 3508 (77.46) & \multirow[t]{3}{*}{$<0.001$} \\
\hline Ever & $69(3.13)$ & $121(2.67)$ & \\
\hline Current & 314 (14.22) & 900 (19.87) & \\
\hline \multicolumn{4}{|l|}{ Alcohol drinking } \\
\hline No & 1822 (83.27) & 3608 (80.55) & \multirow[t]{2}{*}{0.027} \\
\hline Yes & $366(16.73)$ & $871(19.45)$ & \\
\hline \multicolumn{4}{|l|}{ Salt appetite } \\
\hline Moderate & 1135 (51.24) & 2479 (54.52) & \multirow[t]{3}{*}{0.036} \\
\hline Salty & $469(21.17)$ & $916(20.15)$ & \\
\hline Light & $611(27.58)$ & 1152 (25.34) & \\
\hline \multicolumn{4}{|l|}{ Milk consumption } \\
\hline Yes & 837 (42.02) & 1965 (45.55) & \multirow[t]{2}{*}{0.009} \\
\hline No & $1155(57.98)$ & $2349(54.45)$ & \\
\hline \multicolumn{4}{|l|}{ Diet patterns† } \\
\hline Balanced & 1662 (74.73) & 3484 (76.32) & \multirow[t]{3}{*}{0.043} \\
\hline Vegetarian & $403(18.12)$ & $722(15.82)$ & \\
\hline Meat & $159(7.15)$ & 359 (7.89) & \\
\hline \multicolumn{4}{|l|}{ Types of salt $\ddagger$} \\
\hline lodised salt & 2082 (94.38) & 4385 (96.65) & \multirow[t]{2}{*}{$<0.001$} \\
\hline Non-iodised & $124(5.62)$ & $152(3.35)$ & \\
\hline
\end{tabular}

Values are mean \pm SD or $n(\%)$.

*Educational status: primary school group includes illiterate subjects; senior high school group is made up of senior high school and technical secondary school.

†Vegetarian indicates that subjects consistently had a vegetable diet; meat indicates that subjects consistently had a meat diet; moderate indicates that subjects intermittently had a vegetable or meat diet.

łlodised salt indicates that subjects consistently consumed iodised salt; non-iodised salt indicates that subjects intermittently consumed iodised salt or consistently consumed non-iodised salt.

BMI, body mass index.

\section{DISCUSSION}

This study, performed in a large Chinese population, demonstrated that height, weight, BMI and BSA were positively associated with thyroid nodules in adults and children, but only significantly in female adults and children. More explicitly, in the present study, the significant association between high BSA and thyroid nodules was not obviously influenced by sex, age, place of residence and iodine intake.

Thyroid nodules are very common in the general population. The present investigation shows that the prevalence of thyroid nodules was $32.80 \%$ in adults and $10.66 \%$ in children; but they are found clinically in 4$8 \%$ of cases. ${ }^{27}$ In our study, being tall and heavy was 
Table 2 Distributions of sociodemographic characteristics among paediatric patients with and without thyroid nodules

\begin{tabular}{|c|c|c|c|}
\hline Variable & Nodules $(n=257)$ & No nodules $(n=2153)$ & p Value \\
\hline Age, year & $12.01 \pm 2.73$ & $11.06 \pm 3.56$ & $<0.001$ \\
\hline Height, cm & $150.50 \pm 15.84$ & $142.90 \pm 19.68$ & $<0.001$ \\
\hline Weight, kg & $43.83 \pm 11.44$ & $38.56 \pm 14.39$ & $<0.001$ \\
\hline Male & $108(42.02)$ & $1083(50.30)$ & \multirow[t]{2}{*}{0.012} \\
\hline Female & 149 (57.98) & $1070(49.70)$ & \\
\hline Rural area & $104(40.47)$ & $1125(52.25)$ & 0.0004 \\
\hline \multicolumn{4}{|l|}{ Diet pattern* } \\
\hline Balanced & 202 (78.91) & $1663(77.46)$ & \multirow[t]{3}{*}{0.519} \\
\hline Vegetarian & $30(11.72)$ & 271 (12.62) & \\
\hline Meat & $24(9.37)$ & $213(9.92)$ & \\
\hline \multicolumn{4}{|l|}{ Salt appetite } \\
\hline Yes & 192 (80.67) & 1599 (77.73) & \multirow[t]{2}{*}{0.300} \\
\hline No & 46 (19.33) & $458(22.27)$ & \\
\hline \multicolumn{4}{|l|}{ Types of salt $†$} \\
\hline lodised salt & $236(94.02)$ & 2063 (96.58) & \multirow[t]{2}{*}{0.042} \\
\hline Non-iodised & $15(5.98)$ & $73(3.42)$ & \\
\hline
\end{tabular}

significantly associated with thyroid nodules in all adults and women, respectively. However, only the relationship between weight and thyroid nodules was found to be significant in children. To date, few studies have focused on the relationship between anthropometric indexes and thyroid nodules. A previous study ${ }^{28}$ showed that thyroid nodules might share similar risk factors with thyroid cancer: iodine deficiency was associated with an increased incidence of thyroid cancer, largely via benign thyroid conditions such as nodules, which were, in turn, strongly associated with thyroid cancer. In addition, body size might be associated with iodine requirement and therefore indirectly related to the presence of thyroid nodules.

Our results are similar to the findings in 88256 Canadian women in 2012: height was found to be positively associated with the risk of all combined cancers and thyroid cancer, and height was significantly positively associated with risk of thyroid cancer in multivariable models. ${ }^{29}$ Further, the European Prospective Investigation into Cancer and Nutrition (EPIC), a large study including half a million subjects, also observed a positive association between height and thyroid cancer in female but not male subjects. ${ }^{30}$ Beyond these findings from a European population, a pooled analysis of individual data from 12 case-control studies conducted in eight countries (America, Asia and Europe) suggests that height was moderately related to thyroid cancer risk. ${ }^{31}$ In addition, a similar association of height with thyroid nodule risk among Koreans was observed in female but not male subjects. ${ }^{17}$ In our findings on a Chinese population, the moderate association of height with thyroid nodules was also observed in female subjects, which is consistent with the results from Korea in Asia and even a European population. However, the association was not significant in children, but we still found an increased OR for greater height (OR 1.30, $95 \%$ CI 0.89 to 1.90$)$. This may be due to the small numbers of children studied, and therefore the association between height and thyroid nodules in children needs further investigation.

Furthermore, similarly to height, a meta-analysis of data from eight countries also indicated an association of weight with risk of thyroid cancer in female rather than male subjects. ${ }^{31}$ In 2010, Clavel-Chapelon et $a l^{32}$ reported that there was a significant dose-effect relationship between thyroid cancer risk and weight in France. In Asia, a significant association between weight and thyroid nodules in female subjects has been observed in a Korean population. ${ }^{17}$ Our data confirm these findings after adjustment for the relevant covariates. Altered thyroid status has profound effects on skeletal development and growth and on adult bone maintenance. The fact that thyroid hormones are associated with regulation 
Table 3 Adjusted ${ }^{*}$ logistic regression to identify correlations between body size and thyroid nodules in adults

\begin{tabular}{|c|c|c|c|c|}
\hline Variable & Nodules, n (\%) & No nodules, $n$ (\%) & OR $(95 \% \mathrm{Cl})$ & p Value \\
\hline \multicolumn{5}{|l|}{ Pooled } \\
\hline Low & $1334(59.87)$ & $2576(56.43)$ & 1.00 & \\
\hline High & $894(40.13)$ & 1989 (43.57) & 1.15 (1.02 to 1.30$)$ & 0.0245 \\
\hline \multicolumn{5}{|l|}{ Weightł } \\
\hline Low & $1222(54.85)$ & $2760(60.46)$ & 1.00 & \\
\hline High & $1006(45.15)$ & $1805(39.54)$ & $1.40(1.24$ to 1.58$)$ & $<0.0001$ \\
\hline \multicolumn{5}{|l|}{ BMI§ } \\
\hline Low & $1438(64.54)$ & $3351(73.41)$ & 1.00 & \\
\hline High & 790 (35.46) & 1214 (26.59) & 1.26 (1.11 to 1.42$)$ & 0.0003 \\
\hline \multicolumn{5}{|l|}{ BSAף } \\
\hline Low & $1068(47.94)$ & $2675(58.60)$ & 1.00 & \\
\hline High & $1160(52.06)$ & $1890(41.40)$ & 1.43 (1.27 to 1.62$)$ & $<0.0001$ \\
\hline \multicolumn{5}{|l|}{ Female } \\
\hline \multicolumn{5}{|l|}{ Height† } \\
\hline Low & 968 (61.19) & $1596(59.22)$ & 1.00 & \\
\hline High & $614(38.81)$ & 1099 (40.78) & 1.24 (1.07 to 1.44$)$ & 0.0050 \\
\hline \multicolumn{5}{|l|}{ Weight } \\
\hline Low & $946(59.80)$ & $1960(72.73)$ & 1.00 & \\
\hline high & $636(40.20)$ & 735 (27.27) & $1.71(1.47$ to 1.98$)$ & $<0.0001$ \\
\hline \multicolumn{5}{|l|}{ BMI§ } \\
\hline Low & 1002 (63.64) & 2048 (75.99) & 1.00 & \\
\hline High & $580(36.66)$ & 647 (24.01) & $1.47(1.26$ to 01.72$)$ & $<0.0001$ \\
\hline \multicolumn{5}{|l|}{ BSAף } \\
\hline Low & 627 (39.63) & 1366 (50.69) & 1.00 & \\
\hline High & 955 (60.37) & $1329(49.31)$ & 1.53 (1.32 to 1.77$)$ & $<0.0001$ \\
\hline \multicolumn{5}{|l|}{ Male } \\
\hline \multicolumn{5}{|l|}{ Height† } \\
\hline Low & $366(56.66)$ & $980(52.41)$ & 1.00 & \\
\hline High & $280(43.34)$ & $890(47.59)$ & $1.00(0.82$ to 1.24$)$ & 0.9699 \\
\hline \multicolumn{5}{|l|}{ Weight } \\
\hline Low & $276(42.72)$ & $800(42.78)$ & 1.00 & \\
\hline High & $370(57.28))$ & $1070(57.28)$ & $1.00(0.80$ to 1.20$)$ & 0.8690 \\
\hline \multicolumn{5}{|l|}{ BMI§ } \\
\hline Low & 436 (67.49) & 1303 (69.68) & 1.00 & \\
\hline High & $210(32.51)$ & 567 (30.32) & $1.00(0.81$ to 1.23$)$ & 0.9892 \\
\hline \multicolumn{5}{|l|}{ BSAף } \\
\hline Low & $441(68.27)$ & $1309(70.00)$ & 1.00 & \\
\hline High & 205 (31.73) & $561(30.00)$ & $1.21(0.97$ to 1.51$)$ & 0.0871 \\
\hline
\end{tabular}

*Adjustment for age, sex, education, marriage, smoking, alcohol drinking, residence location, types of salt, salt appetite, diet patterns, milk consumption.

†Male: high: height $\geq 170 \mathrm{~cm}$, low: height $<170 \mathrm{~cm}$; female: high: height $\geq 160 \mathrm{~cm}$, low: height $<160 \mathrm{~cm}$.

¥Male: high: weight $\geq 65 \mathrm{~kg}$, low: weight $<65 \mathrm{~kg}$; female: high: weight $\geq 60 \mathrm{~kg}$, low: weight $<60 \mathrm{~kg}$.

$\S L O w=B M l<24.0$; high: $B M l \geq 24$.

१Male: high: $B S A \geq 1.80 \mathrm{~m}^{2}$, low: $B S A<1.80 \mathrm{~m}^{2}$; female: high: $B S A \geq 1.55 \mathrm{~m}^{2}$, low: $B S A<1.55 \mathrm{~m}^{2}$.

$\mathrm{BMI}$, body mass index; BSA, body surface area.

of the growth of long bones may be a possible explanation for the association between height and thyroid nodules. ${ }^{33}$ Moreover, genetic and environmental factors (eg, diet, nutrition) that are correlated with adult height and weight and also influence thyroid function might be another possible explanation for their association. ${ }^{31}$

Analogously, a significant association between BMI and thyroid nodules was observed in the pooled results for adults. A similar association was observed in women, but not men. In children, significant associations of BMI with thyroid nodules were also observed. Our findings in adults are consistent with results in German ${ }^{34}$ and Italian $^{35}$ studies and similar to findings from a Korean population. ${ }^{17}$ However, results from previous prospective and case-control studies on the association of BMI with thyroid cancer risk have generally been more inconsistent in men than women. In a large Norwegian cohort of more than two million, the risk of thyroid cancer increased moderately with increased BMI in both sexes, but the results were not adjusted for smoking and other potential confounders. ${ }^{36}$ After adjustment for key covariates such as cigarette smoking, alcohol drinking, physical 
Table 4 Adjusted* logistic regression to identify correlations between body size and thyroid nodules in children

\begin{tabular}{|c|c|c|c|c|}
\hline Variables & Nodule, n (\%) & No nodules, n (\%) & OR (95\% Cl) & p Value \\
\hline \multicolumn{5}{|l|}{ Pooled } \\
\hline \multicolumn{5}{|l|}{ Height† } \\
\hline Low & $140(54.47)$ & $1259(58.48)$ & 1.00 & \\
\hline High & $117(45.53)$ & $894(41.52)$ & $1.15(0.87$ to 1.53$)$ & 0.3347 \\
\hline \multicolumn{5}{|l|}{ Weightł } \\
\hline Low & $118(45.91)$ & $1175(54.58)$ & 1.00 & \\
\hline High & 139 (54.09) & 978 (45.42) & $1.37(1.03$ to 1.81$)$ & 0.0292 \\
\hline \multicolumn{5}{|l|}{ BMI§ } \\
\hline Low & $106(41.25)$ & $1040(48.30)$ & 1.00 & \\
\hline High & $151(58.75)$ & $1113(51.70)$ & 1.38 (1.04 to 1.83$)$ & 0.0248 \\
\hline \multicolumn{5}{|l|}{ BSAף } \\
\hline Low & 77 (29.96) & 1144 (52.22) & 1.00 & \\
\hline High & $180(70.04)$ & 1009 (47.78) & 2.97 (1.85 to 4.77$)$ & $<0.0001$ \\
\hline \multicolumn{5}{|l|}{ Girls } \\
\hline \multicolumn{5}{|l|}{ Height† } \\
\hline Low & 79 (53.02) & $643(60.09)$ & 1.00 & \\
\hline High & 70 (46.98) & 427 (39.91) & 1.30 (0.89 to 1.90$)$ & 0.1719 \\
\hline \multicolumn{5}{|l|}{ Weightł } \\
\hline Low & $63(42.28)$ & $555(51.87)$ & 1.00 & \\
\hline High & 86 (57.72) & $515(48.13)$ & 1.55 (1.07 to 2.25$)$ & 0.0218 \\
\hline \multicolumn{5}{|l|}{ BMI§ } \\
\hline Low & $63(42.28)$ & $488(45.61)$ & 1.00 & \\
\hline High & $86(57.72)$ & $582(54.39)$ & 1.25 (0.86 to 1.81$)$ & 0.2391 \\
\hline \multicolumn{5}{|l|}{ BSAף } \\
\hline Low & $43(28.86)$ & $556(51.96)$ & 1.00 & \\
\hline High & $106(71.17)$ & $514(48.04)$ & $3.36(1.82$ to 6.20$)$ & 0.0001 \\
\hline \multicolumn{5}{|l|}{ Boys } \\
\hline \multicolumn{5}{|l|}{ Height† } \\
\hline Low & $61(56.48)$ & $616(56.88)$ & 1.00 & \\
\hline High & 47 (43.52) & 467 (43.12) & 0.97 (0.63 to 1.49$)$ & 0.8870 \\
\hline \multicolumn{5}{|l|}{ Weight‡ } \\
\hline Low & $55(50.93)$ & $620(57.25)$ & 1.00 & \\
\hline High & $53(49.07)$ & $463(42.75)$ & 1.15 (0.75 to 1.77$)$ & 0.5120 \\
\hline \multicolumn{5}{|l|}{ BMI§ } \\
\hline Low & $43(39.81)$ & $552(50.97)$ & 1.00 & \\
\hline High & $65(60.19)$ & $531(49.03)$ & 1.59 (1.03 to 2.44$)$ & 0.0355 \\
\hline \multicolumn{5}{|l|}{ BSAף } \\
\hline Low & $34(31.48)$ & $588(54.29)$ & 1.00 & \\
\hline High & 74 (68.52) & 495 (45.71) & 2.57 (1.25 to 5.28$)$ & 0.0104 \\
\hline
\end{tabular}

*Adjustment for age, sex, residence location, types of salt, salt appetite, diet patterns, milk consumption.

†High: height or weight $\geq$ reference standard; low: height or weight $<$ reference standard.

†High: height or weight $\geq$ reference standard; low: height or weight $<$ reference standard.

$\S$ The reference height and weight were used to calculate the BMI reference.

qMale: high: $B S A \geq 1.26 \mathrm{~m}^{2}$, low: $B S A<1.26 \mathrm{~m}^{2}$; female: high: $B S A \geq 1.22 \mathrm{~m}^{2}$, low: $B S A<1.22 \mathrm{~m}^{2}$.

Mean of male $B S A=1.26 \mathrm{~m}^{2}$; mean of female $B S A=1.22 \mathrm{~m}^{2}$.

$\mathrm{BMI}$, body mass index; BSA, body surface area.

activity and medical history of diabetes, the largest prospective study conducted in the USA also found a significant positive association between BMI and thyroid cancer risk in women. ${ }^{37}$ Moreover, a systematic review conducted by Peterson et $a l^{88}$ in 2012 (including 37 studies) showed that most of the studies confirmed a positive association of BMI with thyroid cancer in both sexes. The inconsistent results between men and women in previous studies are probably due to smaller numbers of cases in men and the lack of control for important covariates (eg, cigarette smoking, alcohol intake).
Current smoking and alcohol intake are associated with BMI. ${ }^{39-42}$ Lack of adjustment for smoking status or alcohol drinking may be an important bias in the association between BMI and risk of thyroid nodules. The present study covered adults and children, and the associations of BMI with thyroid nodules were consistent in adults and children after adjustment for important covariates. Based on large samples and reducing important biases, our findings indicate that overweight and obesity are associated with thyroid nodules in both adults and children. The association may be a metabolic 
consequence of excess adipose tissue. Leptin produced by adipocytes has important influences on central regulation of thyroid function through stimulation of thyrotropin-releasing hormone. This seems to be important for downregulation of thyroid function in states of energy deficits, but the importance for modulation of thyroid function under more physiological conditions is uncertain. ${ }^{43}{ }^{44}$ In addition, thyroid hormones may be a significant determinant of sleeping energy expenditure in subjects without overt thyroid dysfunction. ${ }^{45}$ Similarly, differences in thyroid function, within what is considered the normal range, are associated with differences in BMI, caused by longstanding minor alterations in energy expenditure ${ }^{13}$ What is more, obesity is associated with insulin resistance and increased production of insulin and insulin-like growth factors, which in turn have been reported to be associated with thyroid disorders. ${ }^{2} 4647$

Similarly to thyroid cancer, ${ }^{2} 37$ thyroid nodules are more common in women than in men. ${ }^{48-52}$ Sex differences in the association between BMI and thyroid cancer have been confirmed in other studies. ${ }^{31} 53 \quad 54$ Similar results were observed in a Korean study. ${ }^{17}$ Patients who were normal or overweight according to BMI subgroup were identified as having a higher frequency of thyroid nodules. However, no significant relationship between body size and thyroid nodules was observed in men. Our findings in adults were consistent with a sex difference in the association of BMI with thyroid nodules. The difference in thyroid nodule incidence between the two genders suggests that growth and progression of thyroid tumours is influenced by sex hormones, particularly oestrogen. ${ }^{55}{ }^{56}$ However, sex differences in the correlation between body size and thyroid nodules were not obvious in children. This may due to the smaller difference in sex hormones in children compared with adults. Few studies have noted a correlation between body size and thyroid nodules in children; our findings in children require further investigation.

BSA is a better indicator of circulating blood volume, oxygen consumption and basal energy expenditure than BMI or weight. ${ }^{57}$ In the present study, BSA was significantly associated with thyroid nodules in adults and children. The association was not influenced by sex, age, place of residence and iodine intake. A positive association of thyroid cancer with current BSA was consistently found in adults by Suzuki et al in Japan in both sexes after adjustment for the main covariates. ${ }^{58}$ In addition, it has been reported that BSA plays a dominant role in thyroid cancer risk and explains the apparent role of $\mathrm{BMI}$ in adults. ${ }^{57}$ Muscle is more dense than fat, and BMI is not able to differentiate increased weight. ${ }^{59} \mathrm{BSA}$ is a more accurate measure of obesity, including central obesity, as it is a measurement of area and is able to account for the difference between muscle and fat better than BMI secondary to muscle versus fat. ${ }^{21}$ In many ways, the association between BSA and thyroid nodules more strongly confirms the increased risk of thyroid nodules with overweight and obesity than the association between BMI and thyroid nodules.

Considering the potential selection bias introduced by subjects with thyroid problems, we re-evaluated the associations of height, weight, BMI and BSA with thyroid nodules after excluding subjects with diagnosed thyroid disease (see online supplementary tables S3 and S4). Our analyses showed that the associations were very similar to our findings before excluding these subjects. Moreover, we observed similar associations of anthropometric measurements with thyroid nodules when considering quartiles as cut-off points (see online supplementary table S2). Our findings indicate that higher anthropometric measurements are significantly associated with thyroid nodules in Chinese. Further, our study was performed in large populations of adults and children. In addition, weight and standing height were measured using a standardised protocol by a trained examiner rather than being self-reported, reducing the bias of overestimation or underestimation of height and weight. ${ }^{6061}$ Moreover, all participants were screened for thyroid nodules via ultrasonography, reducing the potential for screening bias. In addition, in order to reduce possible bias, we adjusted for most main covariates, including cigarette smoking and alcohol drinking, two important factors that influence overweight. ${ }^{39-42}$ In particular, salt type, salt appetite and diet patterns were taken as covariates in the analytical models; the effect of iodine on risk of thyroid nodules was considered. Hence, the associations of anthropometric measurements were robust.

\section{LIMITATIONS OF STUDY}

There were several limitations in this study. First, waist and hip circumferences were not measured, which hampered examination of the association of central adiposity with thyroid nodules. Second, the number and mass of the thyroid nodules were not recorded, and the thyroid nodules were not classified. Therefore it was not possible to determine different associations between anthropometric measurements and different kinds of thyroid nodule. Also, the age difference between the subjects with and without thyroid nodules may be a potential bias.

\section{CONCLUSION}

We found that thyroid nodule risk increased with weight, height, BMI and BSA, especially in female subjects. Similar trends in relationships between thyroid nodules and weight, BMI and BSA were observed in children. Of the four indicators, BSA was mostly strongly associated with the presence of thyroid nodules. It implies that individuals who are tall and obese have higher susceptibility to thyroid nodules.

Author affiliations

${ }^{1}$ Department of Endemic Diseases Control and Prevention, Hangzhou Center for Disease Control and Prevention, Hangzhou, Zhejiang, China 
${ }^{2}$ Department of Epidemiology \& Health Statistics, School of Public Health, School of Medicine, Zhejiang University, Hangzhou, Zhejiang, China ${ }^{3}$ Shangcheng Center for Disease Control and Prevention, Hangzhou, Zhejiang, China

Contributors YY generated the idea and modified and edited the manuscript. WX supervised the study field activities and prepared and managed the datasets. ZC performed statistical analyses and made a draft of the manuscript. HL, NL, LH, YH, XJ, JD, SZhu and SZha enrolled and interviewed study subjects in the study field.

Funding The study was funded in part by grants from Hangzhou Science and Technology Bureau (Grant number 200908033B27) and the Ministry of Science and Technology (Grant number 2011CB503706). We thank the staff of Hangzhou Center for Disease Control and Prevention for collecting the epidemiological data and blood specimens. We would like particularly to thank all the participants and their families for their contributions and support.

Competing interests None declared.

Patient consent Obtained.

Ethics approval Obtained.

Provenance and peer review Not commissioned; externally peer reviewed.

Data sharing statement No additional data are available.

Open Access This is an Open Access article distributed in accordance with the Creative Commons Attribution Non Commercial (CC BY-NC 4.0) license, which permits others to distribute, remix, adapt, build upon this work noncommercially, and license their derivative works on different terms, provided the original work is properly cited and the use is non-commercial. See: http:// creativecommons.org/licenses/by-nc/4.0/

\section{REFERENCES}

1. Leitzmann MF, Brenner A, Moore SC, et al. Prospective study of body mass index, physical activity and thyroid cancer. Int $J$ Cancer 2010;126:2947-56.

2. Tae HJ, Lim DJ, Baek KH, et al. Diagnostic value of ultrasonography to distinguish between benign and malignant lesions in the management of thyroid nodules. Thyroid 2007;17:461-6.

3. WHO. Media Center: Obesity and overweight. Secondary Media Center: Obesity and overweight, 2012.

4. Colditz GA, Willett WC, Rotnitzky A, et al. Weight gain as a risk factor for clinical diabetes mellitus in women. Ann Intern Med 1995;122:481-6.

5. Calle EE, Thun MJ, Petrelli JM, et al. Body-mass index and mortality in a prospective cohort of U.S. adults. N Engl J Med 1999;341:1097-105.

6. Saw SM, Rajan U. The epidemiology of obesity: a review. Ann Acad Med Singapore 1997;26:489-93.

7. WHO. Obesity: preventing and managing the global epidemic-repor of a WHO consultation. World Health Organization, 2000.

8. Reynolds K, Gu D, Whelton PK, et al. Prevalence and risk factors of overweight and obesity in China. Obesity (Silver Spring) 2007;15:10-8.

9. Sari R, Balci MK, Altunbas $\mathrm{H}$, et al. The effect of body weight and weight loss on thyroid volume and function in obese women. Clin Endocrinol 2003;59:258-62.

10. Michalaki MA, Vagenakis AG, Leonardou AS, et al. Thyroid function in humans with morbid obesity. Thyroid 2006;16:73-8.

11. De Pergola G, Ciampolillo A, Paolotti S, et al. Free triiodothyronine and thyroid stimulating hormone are directly associated with waist circumference, independently of insulin resistance, metabolic parameters and blood pressure in overweight and obese women. Clin Endocrinol (Oxf) 2007;67:265-9.

12. Bastemir M, Akin F, Alkis $\mathrm{E}$, et al. Obesity is associated with increased serum TSH level, independent of thyroid function. Swiss Med Wkly 2007;137:431-4.

13. Knudsen N, Laurberg $\mathrm{P}$, Rasmussen LB, et al. Small differences in thyroid function may be important for body mass index and the occurrence of obesity in the population. J Clin Endocrinol Metab 2005:90:4019-24.

14. Al-Adsani H, Hoffer LJ, Silva JE. Resting energy expenditure is sensitive to small dose changes in patients on chronic thyroid hormone replacement. J Clin Endocrinol Metab 1997;82:1118-25.
15. Guth $\mathrm{S}$, Theune $U$, Aberle J, et al. Very high prevalence of thyroid nodules detected by high frequency $(13 \mathrm{MHz})$ ultrasound examination. Eur J Clin Invest 2009;39:699-706.

16. Zhu HF, Yang Y, Li JY, et al. [Prevalence of thyroid nodules and influencing factors among employees of a company in Qingdao]. Zhonghua Yu Fang Yi Xue Za Zhi 2012;46:228-32.

17. Kim JY, Jung EJ, Park ST, et al. Body size and thyroid nodules in healthy Korean population. J Korean Surg Soc 2012;82: 13-17.

18. Chen $\mathrm{Z}, \mathrm{Xu} \mathrm{W}$, Huang $\mathrm{Y}$, et al. Associations of noniodized salt and thyroid nodule among the Chinese population: a large cross-sectional study. Am J Clin Nutr 2013;98:684-92.

19. Zhou BF, Cooperative Meta-Analysis Group of the Working Group on Obesity in C. Predictive values of body mass index and wais circumference for risk factors of certain related diseases in Chinese adults--study on optimal cut-off points of body mass index and waist circumference in Chinese adults. Biomed Environ Sci 2002;15:83-96.

20. Li H, Ji CY, Zong XN, et al. Height and weight standardized growth charts for Chinese children and adolescents aged 0 to 18 years. Zhonghua Er Ke Za Zhi 2009;47:487-92.

21. Roy SK, Zeb I, Kadakia J, et al. Body surface area is a predictor of coronary artery calcium, whereas body mass index is not. Coron Artery Dis 2012;23:113-17.

22. Mickuviene N, Krasauskiene A, Kazanavicius G. [The results of thyroid ultrasound examination in randomly selected schoolchildren] Medicina (Kaunas) 2006;42:751-8.

23. Gehan EA, George SL. Estimation of human body surface area from height and weight. Cancer Chemother Rep 1970;54:225-35.

24. Haycock GB, Schwartz GJ, Wisotsky DH. Geometric method for measuring body surface area: a height-weight formula validated in infants, children, and adults. J Pediatr 1978;93:62-6.

25. Mosteller RD. Simplified calculation of body-surface area. N Engl J Med 1987;317:1098.

26. Livingston $\mathrm{EH}$, Lee S. Body surface area prediction in normal-weight and obese patients. Am J Physiol Endocrinol Metab 2001;281: E586-91.

27. Tan $\mathrm{GH}$, Gharib H. Thyroid incidentalomas: management approaches to nonpalpable nodules discovered incidentally on thyroid imaging. Ann Intern Med 1997;126:226-31.

28. Dal Maso L, Bosetti C, La Vecchia C, et al. Risk factors for thyroid cancer: an epidemiological review focused on nutritional factors. Cancer Causes Control 2009;20:75-86.

29. Kabat GC, Heo M, Kamensky V, et al. Adult height in relation to risk of cancer in a cohort of Canadian women. Int $J$ Cancer 2013;132:1125-32

30. Rinaldi S, Lise M, Clavel-Chapelon F, et al. Body size and risk of differentiated thyroid carcinomas: Findings from the EPIC study. Int Cancer 2012;131:E1004-14

31. Dal Maso L, La Vecchia C, Franceschi S, et al. A pooled analysis of thyroid cancer studies. V. Anthropometric factors. Cancer Causes Control 2000;11:137-44.

32. Clavel-Chapelon F, Guillas G, Tondeur L, et al. Risk of differentiated thyroid cancer in relation to adult weight, height and body shape over life: the French E3N cohort. Int $J$ Cancer 2010;126:2984-90.

33. Gogakos Al, Duncan Bassett JH, Williams GR. Thyroid and bone. Arch Biochem Biophys 2010;503:129-36.

34. Karger S, Schotz S, Stumvoll M, et al. Impact of pregnancy on prevalence of goitre and nodular thyroid disease in women living in a region of borderline sufficient iodine supply. Horm Metab Res 2010;42:137-42.

35. Trimboli $\mathrm{P}$, Rossi $\mathrm{F}$, Thorel $\mathrm{F}$, et al. One in five subjects with normal thyroid ultrasonography has altered thyroid tests. Endocr $J$ 2012;59:137-43.

36. Engeland A, Tretli S, Akslen LA, et al. Body size and thyroid cancer in two million Norwegian men and women. $\mathrm{Br} J$ Cancer 2006;95:366-70.

37. Kitahara CM, Platz EA, Freeman LE, et al. Obesity and thyroid cancer risk among U.S. men and women: a pooled analysis of five prospective studies. Cancer Epidemiol Biomarkers Prev 2011;20:464-72.

38. Peterson E, De P, Nuttall R. BMI, diet and female reproductive factors as risks for thyroid cancer: a systematic review. PLOS ONE 2012;7:e29177.

39. Chiolero A, Faeh D, Paccaud F, et al. Consequences of smoking for body weight, body fat distribution, and insulin resistance. Am J Clin Nutr 2008;87:801-9.

40. Flegal KM, Troiano RP, Pamuk ER, et al. The influence of smoking cessation on the prevalence of overweight in the United States. N Engl J Med 1995;333:1165-70. 
41. Wannamethee SG, Shaper AG. Alcohol, body weight, and weight gain in middle-aged men. Am J Clin Nutr 2003;77:1312-17.

42. Hou X, Jia W, Bao Y, et al. Risk factors for overweight and obesity, and changes in body mass index of Chinese adults in Shanghai. BMC Public Health 2008;8:389.

43. Chan JL, Heist K, DePaoli AM, et al. The role of falling leptin levels in the neuroendocrine and metabolic adaptation to short-term starvation in healthy men. J Clin Invest 2003;111:1409-21.

44. LaMarca A, Volpe A. Recombinant human leptin in women with hypothalamic amenorrhea. N Engl J Med 2004;351:2343; author reply 43.

45. Astrup A, Buemann B, Christensen NJ, et al. The contribution of body composition, substrates, and hormones to the variability in energy expenditure and substrate utilization in premenopausal women. J Clin Endocrinol Metab 1992;74:279-86.

46. Volzke H, Friedrich N, Schipf S, et al. Association between serum insulin-like growth factor-I levels and thyroid disorders in a population-based study. J Clin Endocrinol Metab 2007;92:4039-45.

47. Vella V, Sciacca L, Pandini G, et al. The IGF system in thyroid cancer: new concepts. Mol Pathol 2001;54:121-4.

48. Mazzaferri EL, de los Santos ET, Rofagha-Keyhani S. Solitary thyroid nodule: diagnosis and management. Med Clin North Am 1988;72:1177-211.

49. Mazzaferri EL. Management of a solitary thyroid nodule. $N$ Engl J Med 1993;328:553-9.

50. Hurtado-Lopez LM, Basurto-Kuba E, Montes de Oca-Duran ER et al. Prevalence of thyroid nodules in the Valley of Mexico. Cir Cir 2011;79:114-17.

51. Yoon DY, Chang SK, Choi CS, et al. The prevalence and significance of incidental thyroid nodules identified on computed tomography. J Comput Assist Tomogr 2008;32:810-15.

52. Bartolotta TV, Midiri M, Runza G, et al. Incidentally discovered thyroid nodules: incidence, and greyscale and colour Doppler pattern in an adult population screened by real-time compound spatial sonography. Radiol Med 2006;111:989-98.

53. Guignard R, Truong $T$, Rougier $Y$, et al. Alcohol drinking, tobacco smoking, and anthropometric characteristics as risk factors for thyroid cancer: a countrywide case-control study in New Caledonia. Am J Epidemiol 2007;166:1140-9.

54. Brindel P, Doyon F, Rachedi F, et al. Anthropometric factors in differentiated thyroid cancer in French Polynesia: a case-control study. Cancer Causes Control 2009;20:581-90.

55. Negri E, Ron E, Franceschi S, et al. A pooled analysis of case-control studies of thyroid cancer. I. Methods. Cancer Causes Control 1999;10:131-42.

56. Renehan AG, Tyson M, Egger M, et al. Body-mass index and incidence of cancer: a systematic review and meta-analysis of prospective observational studies. Lancet 2008;371: 569-78

57. Clero E, Leux C, Brindel P, et al. Pooled analysis of two case-contro studies in New Caledonia and French Polynesia of body mass index and differentiated thyroid cancer: the importance of body surface area. Thyroid 2010;20:1285-93.

58. Suzuki T, Matsuo K, Hasegawa Y, et al. Anthropometric factors at age 20 years and risk of thyroid cancer. Cancer Causes Control 2008;19:1233-42.

59. Hamdy O, Porramatikul S, Al-Ozairi E. Metabolic obesity: the paradox between visceral and subcutaneous fat. Curr Diabetes Rev 2006;2:367-73

60. Gunnell D, Berney L, Holland P, et al. How accurately are height, weight and leg length reported by the elderly, and how closely are they related to measurements recorded in childhood? Int $J$ Epidemiol 2000;29:456-64

61. Niedhammer I, Bugel I, Bonenfant S, et al. Validity of self-reported weight and height in the French GAZEL cohort. Int $J$ Obes Relat Metab Disord 2000;24:1111-18. 